\title{
Specificity and pervasiveness of dialogues in Science, Technology and Innovation policies in Spain
}

Special Issue: "The voices of the STI communities: understanding dialogue processes to build public policy" Special Issue Editors: Gabriela Dutrénit and José Miguel Natera

\begin{abstract}
A process of dialogue often precedes the design of Science, Technology and Innovation (STI) policies. The scope and variety of targets and actors involved, are key factors helpful in the characterization of dialogues. This paper explores specificity and pervasiveness as distinguishing analytical attributes of dialogues in the STI field. This point is illustrated through a case study of two dialogues that took place over the last decade in Spain. One responds to a top-down approach in policy building; the result has been a multi-year regional R\&D plan. While the geographical scope is here reduced, the pervasiveness of the topic prevails. The second dialogue has its roots in a large Spanish firm playing as promoter; a clear case of bottom-up dialogue. The target was the reinforcement of university/industry relationships, ultimately ending in new labour regulation. Specificity is a defining attribute of this dialogue, although the expansive result affects the national space.
\end{abstract}

Key words: Dialogue; Science, Technology and Innovation Policy; System of Innovation; Triple Helix. 


\section{Introduction}

Science, technology and innovation (STI) policies have gained considerable relevance in the public agendas of governments, especially since the 1980s. In Spain, the first Law of Science was consolidated in 1986 and since that time, research and development (R\&D) has become an aspect of social debates and public concerns (Sanz \& Muñoz, 1994; Garcia Arroyo et al., 2007). Agreement around the role of STI policies and innovation concerns in terms of the development of countries is now wide and general, and consensus is broad on the positive effects that $R \& D$ expenditures, innovation, patents, and a skilled labour force may have on economic growth. However, even though the results of an effective STI policy have been proven positive for countries, the role that the various actors within society may play in the process of building such policies remains unclear. In particular, the literature on STI has yet to devote much attention to understanding the process of dialogue that makes possible the building of a robust STI policy (Brown, 2015; Chilvers, J., 2012; Crespi and Dutrenit, 2013).

Through the Innovation System (IS) and the Triple Helix conceptual frameworks, dialogues among different actors within societies may take place as previous phases toward the definition of STI policies. A variety of actors can be involved, and these range from firms and bodies of the public sector to universities, research centres, and civil and social sectors (Lundvall, 2007; 2009; Etzkowitz and Leydsdorff 1995; Ranga and Etzkowitz, 2014). The dialogue is then assumed here as a mechanism for policy articulation, and this paper aims to understand how the interactions between actors contribute the building of STI policies. The research objective is to introduce a new approach of STI policy through an analytical construction that may contribute to the dialogue' methodology development. This is an aspect gaining increasing attention and is considered by recent initiatives such as the OECD's projects in the Latin American region (OCDE, 2011), or those in the CYTED-Lalics network ("Red Temática para Mejorar el Diálogo entre las Comunidades Involucradas en las Políticas de CTI”; website: http://www.cyted.org/?q=es/detalle_proyecto\&un=883).

The scope of such dialogue can be specific, aimed the topic addressed or the geographical location affected, or it can conciliate the interests of a large number of heterogenous actors, making possible the generalization of effects throughout the national geography. The leading actor adopts the role of promoter, in a process of 
variable duration, meanwhile seeking agreement from a multiplicity of agents. Moreover, the direction of the dialogue may differ: it can be generated bottom-up, at the level of the actors directly implicated, or it can be top-down, motivated by the bodies responsible for STI policy.

The study of two dialogues successfully implemented in the last decades in Spain allows us to observe the relevant aspects in the articulation of STI policy. The consequence is an ex-post analytical construction based on two main axes: the diversity of interest among the actors involved in the process and the extent of the effects in the field of STI policy. The combination of them derives on the observation of specificity versus pervasiveness as two relevant analytical attributes of the dialogue process. Specificity means a particular interest, with few actors involved and a specific objective. Pervasiveness implies a great variety of both interests and actors, toward of a more general objective. The definition of a dialogue according to these two aspects emerges from the observation of the dialogue's initial conditions and the outcome in terms of STI policy.

The research question here is to what extent original features of the dialogue process (direction, actors and their interactions, interests, topic, scope) and its outcomes and effects, permit to identify patterns of dialogue for the building of STI policy. A description of two dialogues through the use of case study is followed to observe commons features that define an ex-post analytical construction to classify dialogues according to specificity and pervasiveness. The final implication would be to contribute to the dialogue' methodology based on good practices in the field of dialogues for STI policy practitioners, which could then be translated and generalised to both other policies and countries, thus contributing to the development of a method leading to build more effective STI policies.

The criteria to select the dialogues under study have been the following. First, the two dialogues are different and they have taken place in the context of Spain in the last decades: The first one is the Dialogue for the building the 2020 Regional Plan for Innovation in Andalusia; secondly, the Dialogue for researcher mobility from university to firms promoted by the multinational enterprise Iberdrola. Both of them have ended with the implementation of actions in the STI policy domain. In this sense, it should be noticed that this study focuses on the process of dialogue itself and not in the evaluation of STI policies and their ex-post impacts. Moreover, the selection of these two dialogues 
has been done according to their direction (top-down or bottom-up), their qualitative nature and the relevance of the dealing topic and the revealed weaknesses of the Spanish system. While the regional dialogue is selected due to the existent regional competences in STI policy and its top-down approach, the Iberdrola dialogue was selected due to its relation with the identified lack of interactions between university and industry, and also the lack of employment opportunities for highly qualified researchers within the national context. Therefore, the combined study of these two dialogues guarantees that they differ in the original direction, topic, geographical scope level of diversity, and the outcomes of the process process.

The rest of this paper will be arranged as follows. Section two reviews the background on the connection between the process of a multi-actor dialogue and the elaboration of STI policies. Section three describes two cases of dialogues in the field of STI that have taken place in Spain. Fourth and fifth sections consider the implications derived from our analysis, drawing conclusions and recommending further research.

\section{Background: Dialogue and STI policy}

Some concerns exist at the international level about the increasing role that dialogues involving different actors have acquired in the design and implementation of public policies. This applies also to the particular case of STI. In this regard, some authors have already recognized that the discussion and interaction among different actors during the elaboration of these policies will facilitate their final implementation, by introducing real technological concerns and social needs into the dialogue process (Brown, 2015; Chilvers, J., 2012; Crespi and Dutrenit, 2013; Sutz, 1993).

More than three decades after the pioneering works on innovation systems (IS) were published (Freedman, 1987; Lundvall, 1988; 1992; Nelson 1992; 1993), this remains a major framework of reference for the design and implementation of STI policies. In this approach, it is agreed that the IS might be defined as a set of political, social, economic and cultural factors that allow the development of a country, region or sector through knowledge (Nelson, 1993; Lundvall, 2007). Part of this literature stream has focused on the actors of the IS, among which may be included firms, the public sector (governments), universities or research centres, and social actors (Lundvall, 2007; Castellacci and Natera, 2012). On the other hand, a significant portion of contributions 
to the stream has focused on the study of interactions among actors as an engine for the generation and diffusion of knowledge, and the achievement of innovations. The Triple Helix concept also shows the relevance of university-industry and government relationships as an engine for innovation and economic development in the Knowledge society (Lowe; 1982: Sábato and Mackenzi, 1982; Etzkowitz, 1993; Etzkowitz and Leydsdorff 1995). Contributions in this line have explored the complexity of innovation dynamics, informing about national, regional and international innovation and the key aspects for the development of policy-making processes.

In the innovation system framework, three main pillars are identifiable (Fagerberg and Sapprasrt, 2011): The first pillar was built around the variable nature of the determinants of economic development, underlying the role of networks and synergies among scientific institutions, industrial sectors, policies and cultural roots (Freedman's ideas). Secondly, Lundvall developed the concept of learning as an evolutionary process that is determined by the interaction of agents with their environment (Lundvall, 2007; 2009). Finally, Nelson developed the institutional approach, which is to say "the rules of the game” of innovation systems (Nelson, 2008). More recently, the concept of IS has also been extended to an internationalized scope, and by taking a more global perspective, new insights have emerged from the viewpoint of developing countries in terms of their policies and institutional settings (Carlsson, 2006; Lundvall et al., 2009; Edquist and Homen, 2008). Within the Triple Helix approach, the (neo) institutional perspective considers that university is the key actor in the framework (Etzkowitz et al., 2005), while the (neo) evolutionary perspective considers University, Industry and Government as a coevolving subset of social system. Moreover, few works also connect the Triple Helix concept with an innovation system framework. The combination of them is identified as a Triple Helix system that will be defined as a set of three elements: the actors involved, their functions and the relationship between them that can be observed through technology transfer, collaboration and conflict moderation, collaborative leadership, substitution or networking (Ranga and Etzkowitz, 2014).

The concept of IS also applied at the regional level, by means of a Regional System of Innovation (RSI); and while this term maintains the main principles, RSIs reduce the scale of application to a sub-national local territory (Cooke, 1992). Therefore, RSI has two points of interest: First of all, the interaction between different actors within the given territory, and secondly the connection between different RSIs within the national 
or global IS in the production of knowledge (Uyarra, 2010). Therefore, the concept of RSI in isolation makes little sense. Moreover, regarding the actors of an IS, one important aspect to be taken into account is that the industrial structure is defined by a heterogeneous set of units, including large as well as small and medium enterprises (SME), along with diverse patterns of innovation, depending on their different sources of relevant knowledge (Pavitt, 1984). Academic and scientific institutions may also present a significant degree of diversity, and this is important to recall in terms of their varied relevance and influence in the development of STI policy (Edquist, 2004; Edquist and Hommen, 1999; Álvarez et al., 2016).

Discussion of public policies emerged in the second half of the 20th century from the interaction of various disciplinary fields, including public administration, economics, political science, and systems theory, partly as a result of a crisis in public administration, and its inability to address both public and governmental problems (De Leon, 1988; Arellano, 1996; Nelson, 2001). Nonetheless, this can be transformed into an opportunity to launch a fruitful analytical approach that permits further study of the process of public policy dialogue (Arellano, 1996). Four important characteristics guide the main research: interest in a full model of political systems and processes; the relevance of the consequences of government actions; efforts to obtain useful knowledge while remaining theoretically and empirically sensible; and the conviction that democracy matters.

Cobb and Elder (1972) point out that it is essential to recognize, in the case of a problem subject to public intervention, the distinction between the public agenda and the government's agenda. Here the public agenda is a set of concerns raised by the members of a political community, reflecting issues that fall within the responsibilities of government. On the other hand, Aguilar (1992) indicates that the government agenda consists of all issues that have been accepted by policy-makers. The distinction between government and public agendas represents the level of abstraction in the formulation of a problem, and the government agenda tends to be more limited, specific and concrete. Nonetheless, it can be noted that government intervention in a problem integrated into the public agenda must be translated and defined in terms that allow for a feasible solution.

Bridging the gap between the public and government agendas gives space to the role of dialogue. The dialogue process in public policy adopts various definitions and 
approaches. Lasswell and Lerner (1951) noted that this process is based on creativity, and consists of five phases: recommendation, prescription, invocation, implementation and completion. Moreover, Anderson (2003) defined the dialogue process as a sequential pattern of activity in which a number of categories can be distinguished analytically, although not necessarily on a temporal or sequential basis. These include the problems of identification and management of the agenda, policy formulation, policy-making, implementation and evaluation. Other prevalent approaches have characterized the process of political dialogue as a set of activities aimed at solving problems, and public decision-making is divided into different steps ranging from a sense of perplexity or wonder at an event, including the very definition the problem, up to experimentation with the option selected (Nelson, 2001). Meanwhile, all these definitions emphasize a holistic view of the process in the development of public policies, and this concerns institutions, interactions and ideologies.

Some contributions found in the related literature examine the case of science policy in the UK since 1985 (Pieczka and Escobar, 2013). Their objective was to confront the normative drive in policy-making through public communication, public understanding, public engagement and public dialogue, along with the resulting institutional efforts (policy discourse). They discuss how public dialogue in science in the UK becomes a management technique, as a way to re-construct public legitimacy (Pieczka, 2002). Elsewhere, Hellström (1996) examines the use of environmental modelling in policy and its uncertainty, taking the description of the problem of acid rain as a supportive illustration. It is argued that the changing function of science in society inserts a new voice into the science-policy dialogue, and uncertainty in modelling exercises provides new constraints, and possibilities, for STI policies.

Although the dialogue and interactions between different agents in the systems approach is seen as a constitutive element of a STI policy, the dialogue between actors, driving STI policy actions has not been deeply analysed in both the IS and the Triple Helix approaches, until now. This is a key issue, assuming that STI policy should answer citizen concerns as well as the needs of the national system of innovation (Crespi and Dutrenit, 2013). Therefore, some policy makers recommend the opening of spaces for dialogue in the design and implementation of policies at the national or regional levels (OCED, 2011). 
Among the analyses of dialogues between actors for building STI policies, the works of Chilvers (2010; 2012) refer to the role of the actors in the public STI dialogue in Great Britain. Chilvers (2010) recognizes five actors in the dialogue around STI policies: the dialogue practitioners, the academic and social scientists, the dialogue commissioners and policy makers, the scientific institutions, the participation institutions, and the civil society organizations. Other authors claim the role of public participation in the development of STI policies (Durant, 2010; Felt and Focher, 2009), this being understood as a path for the adaptation of technology to social needs (Stirling, 2008), and justifying public participation as an alternative to deficient technocratic approaches (Burgess and Chilvers, 2006).

Reinforcing the role of dialogue in the development of STI policies, a first attempt at classification has been made regarding the public target of the dialogue (OCDE, 2011). In this sense, it is possible to differentiate between three levels of dialogue in the field of STI policy. The first includes that dialogue developed at the highest level of policy, such as the Ministry level, given its involvement in the definition of a national STI strategy. The second level is the technical dialogue, and this refers to the dialogue of policy advisors in the elaboration of the STI policy. The last level refers to the dialogue around the implementation of policy itself.

The research carried out through the works of the CYTED-Lalics Network ("Red Temática para Mejorar el Diálogo entre las Comunidades Involucradas en las Políticas de CTI"; website: http://www.cyted.org/?q=es/detalle_proyecto\&un=883) attempts to compare different dialogues in the field of STI policies in Latin American countries and Spain. The definition of dialogue here used has been adopted from the UNDP and is understood as the process of genuine interaction among human beings, who by respectful listening are able to change through learning. Each participant in the dialogue makes an effort to integrate the worries of the others into their own perspective, even when disagreement prevails. No participant renounces their identity but each acknowledges the other claims and, as a consequence, behaves differently regarding the other participants (UNDP, 2003). The selection of cases of dialogue in Spain was made bearing several aspects in mind: the geographical scope, direction, topic, and level of diversity in the dialogue as well as the extent in terms of STI policy. A case study methodology for the description of two heterogeneous dialogues is applied. We follow the Guidelines pointed out in the analysis of PNUD (2003; 2007) and OCDE (2011). In 
the next section, we first present a dialogue that took place at the regional level with a clear top-down approach, and secondly, a dialogue generated by a large firm which has generated impacts at the national level, although it began as a bottom-up process.

\section{Description of two dialogues in the context of Spain}

3.1. Dialogue for the building the 2020 Regional Plan for Innovation in Andalusia (Plan Andaluz de Investigación, desarrollo e innovación 2020).

Regulation of the Innovation Strategy in Andalusia was included in Spain's first Law of Science and Technology (Ley 13/1986). This law lays out the basis for the elaboration of a national innovation strategy, but it also recognizes that the different administrative regions in Spain (a total of 17 Comunidades Autonomas) have the legal ability and autonomy to develop their own regional innovation strategies, though this must always being done in concordance with European and Spanish innovation policies (Palma., L. et al, 1992). Since that time, Andalusia has developed several Innovation Plans: The first was the Directive Plan for Innovation and Technological Development, during 2001-2003 (Plan Director de Innovación y desarrollo tecnológico para Andalucía, 2001-2003). Also, among others: the Third Research Plan in Andalusia, 2000-2003 (III Plan Andaluz de Investigación, PAI-2000-2003); the Innovation and Modernisation Plan, 2005-2010 (Plan de Innovación y Modernización de Andalucía, PIMA, 20052010); and the Research, Development and Innovation Plan, 2007-2013 (Plan Andaluz de Investigación, Desarrollo e Innovación, PAIDI, 2007-2013). Currently, Andalusia is implementing the Research, Development and Innovation Plan for the period 2014-2020 (Plan Andaluz de Investigación, Desarrollo e Innovación, PAIDI 2014-2020). Here, description of the dialogue will correspond to the development process of the latter the PAIDI 2014-2020.

The motivation for choosing this dialogue in the Spanish context is the fact that Andalusia is an intermediate region in technological terms; for this reason, it is necessary to define and implement policies geared toward catching up with those more technological advanced Spanish regions, and to increase innovation levels and results within the region. This is not locally specific but it may be also seen as a common feature for many European regions in the periphery. In addition, Andalusia can be considered as economically similar to some regions of Latin America, so this 
Autonomous Community of Spain is an interesting territory for comparison with other dialogues, building different Science and Technology policies throughout Latin America.

The principal objective of the Research, Development and Innovation Plan (PAIDI 2014-2020) is that it becomes the main tool for the planning, coordination, promotion and evaluation of R\&D and innovation in the region. With the formulation of PAIDI, the regional government is aiming to set a solid basis for a new model, based on knowledge and innovation and making rational and effective use of material and human resources for employment creation, sustainable development, and social cohesion. Thus the main goals are the promotion of innovation, especially as regards regional economic growth, and the modernization of the traditional productive model in concordance with National and European strategies in the field of STI. Specifically, the PAIDI focuses on a set of sectors that have been identified as strategic to the development of the region: Information and communication technologies (ICT), energy, the food industry, and any other priority sector that enhances technological development. From this primary interest in innovation and growth, a breakdown can be made of various specific targets aimed at promoting innovation in the region. PAIDI also integrates the promotion of competitive research of high quality as well as other programmes aimed to improve the STI indicators at the regional level.

Dialogues previously opened for building the innovation plan permit us to observe two main challenges. The first is the definition of those policy actions necessary to fulfilment of the general target of regional development based on innovation; the second is the design and implementation of public policy actions in accordance with European and Spanish innovation policies. These two challenges determine the diversity of actors involved in the process of dialogue. Heterogeneous actors involved in the dialogue are ranking from the regional government bodies to the individual experts from the business and academia communities.

The dialogue for building the PAIDI began once the previous innovation plan had been executed. Therefore, the new plan was nourished by concerns and results achieved during the previous cycle. From that point, the process of dialogue has attempted to be inclusive of all actors of the regional IS, although these have different levels of 
participation. The participants in this dialogue are described below, in decreasing order according to their level of participation ${ }^{1}$.

The mandate for building this dialogue corresponds to the regional government body; that is to say, is the public sector is the leader, convener and promoter of the dialogue. As Palma et all. (1992) explain, the technological impulse of Andalusia has long been dependent on the public sector. Therefore, the dialogue follows a top-down direction, initiated by the government administration at the regional level. Considering the many public actors involved, it is possible to further differentiate participants at the level of the regional, national and European public sectors. At the first of these levels, it should be mentioned that entire departments of the regional government participate in the elaboration of the plan, given the mainstreaming of the topic included in the plan. The other two participants also take part as a guarantee mechanism for necessary concordance between the regional innovation plan and the national and European policy objectives in the field of technological development and innovation.

Moreover, firms and universities also participate in the process of dialogue, their roles being closely linked to their expertise, as well as the provision of specialized reports, along with participation in meetings and discussions. The participation of firms is also due to is their ability to speak to real technological concerns in the region, given that their technological behaviour depends, at least partially, on external links that innovation policies may be able to promote (García Sánchez et al (2005). Meanwhile, universities in the region take part in the process due to the need for academic and scientific interests to converge with relevant streams of the innovation plan.

Eventually, a first draft of the innovation plan was opened to public consideration, bringing regional STI policy to the attention of citizens ${ }^{2}$. In this part of the process, citizens are able to provide suggestions before the final document is elevated to law and goes into force (following publication in the official bulletin of the region). After this official period for public consultation ${ }^{3}$, PAIDI 2020 was approved in March 2016 by government agreement. Its main impact is the development of the innovation plan for Andalusia until 2020.

\footnotetext{
${ }^{1}$ For the identification of the actors we follow OCDE, 201. The inherent difficulties in the identification of the actors should be noticed given the generalized lack of public information about the elaboration of public policies.

2 http://www.juntadeandalucia.es/boja/2015/215/52

3 http://www.paidi2020.es
} 
In terms of outcomes, this process of dialogue can be seen as highlighting the following issues: it was a continuous process of dialogue that involved all the actors in the regional innovation system. The participation of the public sector came in at three levels: regional, national and European; the first clearly playing the leading role. In addition, at the regional level, all the relevant departments were involved in the development of the innovation plan. The plan incorporated different sectors and targets, therefore this dialogue attempted to influence various interests and aspects related to innovation. These three levels of the public sector point out that this plan has to be a coordinate policy at the European, Spanish and Andalusian level ${ }^{4}$. The regional aspect of this dialogue will not be an obstacle for the dialogue.

The characteristics described above allow us to classify this dialogue as one of great pervasiveness: in the dialogue prior to the plan, all the actors of the IS participated. However, the multiplicity of interests involved in the elaboration of the plan may not be conducive to the main target of innovation growth in the region. In this sense, it is possible to identify 7 specific objectives of the plan: promotion of scientific excellence and quality; fostering and management of talent; orientation of $R \& D$ and innovation toward social concerns in Andalusia; impulse of the knowledge economy; development of the region in term of competitiveness and innovation; promotion of the research and development infrastructures; and improvement of actions for sectoral innovation.

\subsection{Dialogue for researcher mobility from university to firms - Iberdrola (Spain)}

The establishment of a knowledge-based economy demands the expansion of public policy instruments that specifically target both the formation and mobility of human resources in science and technology fields. For this reason, the promotion of mobility among qualified youth within innovation systems is an issue of increasing interest in the design and implementation of public STI policies. Among possible actions is the flow of qualified people between universities and firms. The general assumption is that mobility may enhance synergies in the generation and accumulation of knowledge, and facilitate knowledge transfer within innovation systems.

\footnotetext{
${ }^{4}$ Countries members of the European Union should coordinate innovation policies at the national and regional level as well.
} 
The mobility of staff between universities and companies in Spain has appeared in the formulation of various National Plans for STI since the 1980s. Nonetheless, since the adoption of the first National Plan in 1986, many changes have taken place, and the introduction of new planning tools has been conducted progressively in the context of the country. The target has been the adaptation of public policies for R\&D and innovation to the needs of a dynamic environment, revealing specific needs for the Spanish system of STI itself. One of those revealed needs has been to increase the mobility of researchers from academia to industry; and related to that, the necessity of defining and implementing measures oriented to the recruitment of research trainees in the business sector.

Assuming the role of firms within a system as key actors in innovation, par excellence, it is noteworthy that, among potential mechanisms for sourcing external knowledge, the hiring of trained researchers is very important (Von HIppel, 1988). This mechanism ensures that the contractor has access to human capital with new knowledge and skills that can contribute to raising value and providing exclusive knowledge that may ensure the success of the innovation process.

Among the steps taken in Spain, the national legislation and STI policies began to regulate the training process of doctors integrated into enterprises. The means to proceed have included the co-funding of employment contracts for research trainees while they participate in projects of industrial research or experimental development in the interest of their $\mathrm{PhD}$ thesis. The purpose of such action was to promote the employment of researchers in the business sector from the beginning of their careers, contributing to the employability of young and qualified researchers by promoting the incorporation of new talent into the productive sector, and thus affecting a rise in competitiveness (see for example Real Decreto 63/2006, the National R\&D and Innovation Plan for the period 2004-2007).

Despite some progress on this line of thought and action in Spain, certain gaps in regulation were detected, and these were hampering the mobility of human resources between universities and businesses. Also of importance were the solution of problems of understanding between the two sectors, and of the lack of collaboration between the business and academic community. Notably, these problems were detected by the industries and firms who tried to hire researchers. Such was the case of Iberdrola, a leading company in the Spanish energy sector. For this reason, in the early 2000s, the 
Iberdrola Foundation launched a scholarship program aimed at supporting high quality research.

In fact, the main objective of this Spanish multinational enterprise was even more complex, and the strategy to follow was defined in various lines of action: to promote the training of new researchers; to promote research in the area of renewable energy; to promote the mobility of young doctors and engineers from academia towards industry; and to provide training through a program developed between Spain and the U.S.A.

The impetus given by Iberdrola to mobility motivated a dialogue among policy makers, academics, and the business sector, seeking to overcome the difficulties encountered in regulation of the employability of researchers and the recruitment of talent. The main purpose of this dialogue was to gain legitimacy in the recruitment programs of trained researchers, and in the development of common training programs among universities and companies. The issue was then defined in two lines of action: first, the implementation of specific programs or contracts for the creation of jobs within the company, aimed especially at colleges; and second, the establishment of subsidies granted to training firms, either through sponsorship of educational activities in situ, in collaboration with universities or by the creation of a firm's own campus.

As regard specific characteristics, it can be said that this dialogue has proven innovative, since it seeks to change policies in science and technology toward the promotion of inter-sectorial collaboration and regulation, as well as accreditation and state-support in the financing of fellowship training and research, and the mobility of scientists and researchers from the university to private enterprise. The dialogue has been very pertinent to the present Spanish political and economic context, in view of the current objectives of boosting economic activity, the creation of new jobs, and increasing productivity and competitiveness. In a sense, it is important to establish a permanent social dialogue, alongside the structural reforms to be addressed, as a way of establishing a new and sustainable economic model. With regard to the effects on management of labour and human resources, some of the fundamental axes of action include rotation, mobility and training, career development, and reconciliation with family rights and gender-equity opportunities. In this regard, Iberdrola's strategy since 2002 has anticipated some necessary structural measures, such as the modification of its own models of recruitment, training, and updating industrial relations. 
Meanwhile, in 2002 Iberdrola launched a plan of action, in collaboration with several universities, to promote the employment of young people and to facilitate the mobility of researchers from those universities to the company. As a result, about 700 young persons have been trained in the company as interns, as a step previous to being hired as researchers. Although in 2004 Iberdrola reached an accord with several high education institutions, the company was continually involved in the process of dialogue with the public administration and academic authorities, maintaining its commitment to the university-industry relationship.

An outcome of the dialogue was followed by the signature on May 20, 2013, of the Joint Strategy for Youth Entrepreneurship and Employment 2013-2016 with the Spanish government. Under this agreement, the company developed a Plan of Action aimed primarily at encouraging the recruitment of young researchers for their first professional experience outside the university. Moreover, the process of dialogue that sought to regulate, improve and enhance the employability of researchers trained at universities for work in private companies has also become part of the plan for European science and technology policies (as in the European Framework Programme, or the European Horizon 2020); and this need for mobility of scientific staff-training has also been recognized by the various stakeholders.

The role of Iberdrola in this dialogue has not been without difficulty, since the main challenge was to incorporate a concerted approach to improving the mobility of students and researchers from universities to companies into the Law of Science, Technology and Innovation (the public community). In other words, it was a purely private initiative conceived at Iberdrola (the business community) that eventually came to pervade many other firms and sectors.

The successful aspect of the dialogue is how this issue has been integrated into the actions of public policies in STI, having changed the particular policies that support and regulate mobility. It was not until 2011 that the dialogue had a direct impact on policy STI, Spanish Law 14/2011 at that time being published in Science, Technology and Innovation, a section in which the conditions under which regulations around businesses and pre-doctoral contracts were modified. This result was achieved through the realization of a number of expert meetings and great efforts toward seeking consensus. In the end, this project culminated in a law that regulates how researchers are given a new platform for training, production, and transfer of scientific knowledge, with more 
favourable contractual relationships. Undoubtedly, one of the communities that has benefited most is the business community, because the action encourages young people to enter their ranks, providing salaries to highly qualified scholars, also fostering more efficient processes; regulatory compliance personnel seek innovative solutions that entail economic benefits and improvement of companies’ public image. Nonetheless, potential positive impacts for the innovation system could be seen in the number of applicant calls, the budget allotted, the output obtained (number of papers, patents, etc.), and in the fact that, year after year, new opportunities for young researchers continue to increase.

\section{Discussion}

The description in the previous section of the two dialogues that took place in Spain in recent decades allows us to confirm the differentiated characteristics shown by these processes, as well as the effects obtained as results from both. Two main objectives convene in these dialogues for STI. On the one hand, in the PAIDI 2020 dialogue, the promoter and leader regards innovation as a driving mechanism for development, helping to transform the productive and economic system toward smarter specialization. On the other, the leadership in the Iberdrola dialogue shows this process to be a valid way of resolving systemic problems often detected in innovation systems, especially as regards important linkages and interactions between different agents in the promotion of innovation (in particular, the traditional difficulties encountered in the context of university-industry relationships).

Concerning the conceptual elements that mark differences between them, the PAIDI dialogue provides a good illustration of a top-down process at the regional level, in which economic development is the paramount goal, in line with the Systems of Innovation literature (Lundvall et al., 2009; Fagerberg \& Sapprasrt, 2011). This posits a dialogue involving different angles of the system of innovation, and it illustrates the confluence of government and public agendas in the regional setting, necessarily bridging various fields of public policy. On the other hand, the Iberdrola dialogue responds to a bottom-up process that (in this case) followed from an improvement of interactions between firms and universities, which generated positive effects in the rate of employment among young, qualified researchers in Spain. These differing motivations underline two important conceptual elements within dialogue processes: 
First, the existing relative level of capabilities within the system, and the potential for further capability-building, in the case of developing systems. Second, the targets of problem identification and problem solving which are evident at the core of the dialogue processes analysed here.

Overall, the heterogeneity of actors that can potentially participate and interact in dialogues in the field of STI brings us to consider the ways in which these two dialogues digress. The regional plan involved most of the actors present in the regional system of innovation, as well as a set of more heterogenous actors (see Figure 1a). On the other hand, the Iberdrola dialogue for the mobility of researchers concerned three main actors: a multinational firm, academic institutions, and public administrations (Figure 1b).

Figure 1a. Diversity of actors in the regional dialogue - PAIDI

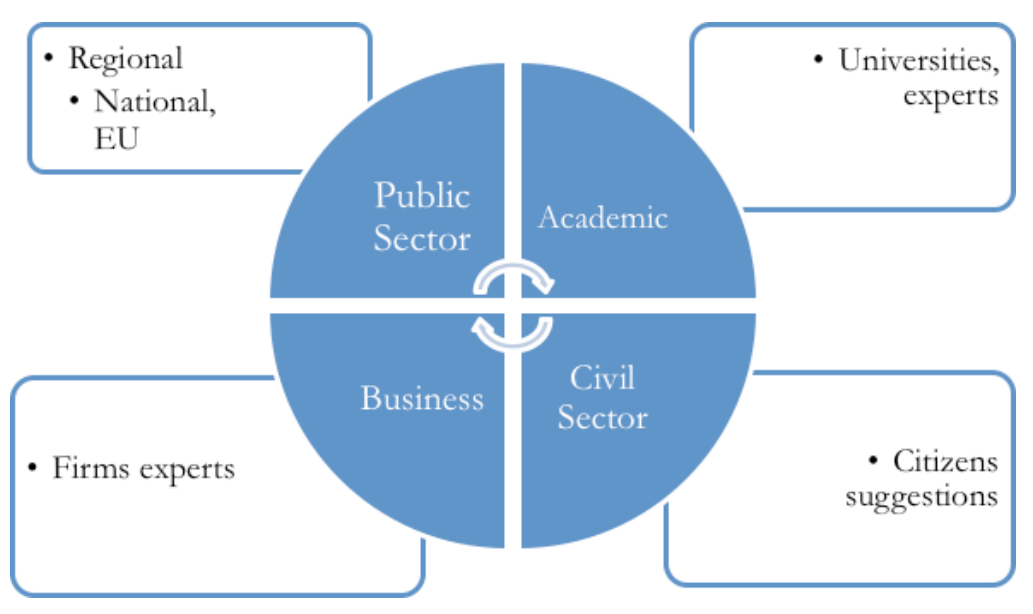

Figure 1b. Diversity of actors in the Iberdrola dialogue

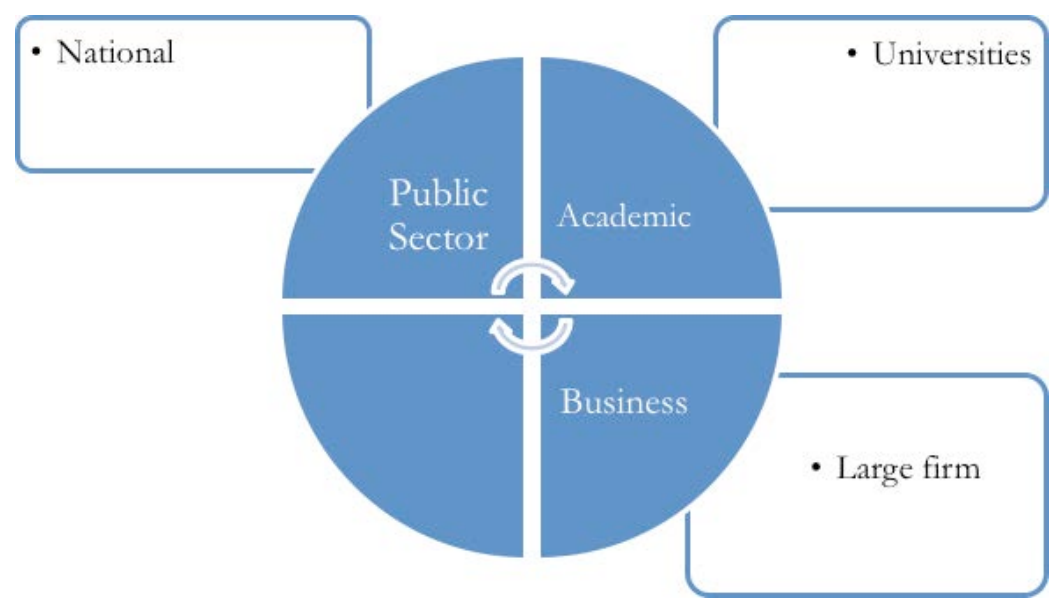

Source: Own elaboration 
Although national and supranational circumstances define the strategic lines of STI, the regional plan follows a top-down approach in which the dialogue is generated by the department in charge of STI within the regional government. The definition of policy actions over a period of four years, with the goal of furthering the level of development in the Andalusia region, implies the conciliation of many different actors and interests. Accordingly, although there is a general interest in the establishment and advance of dialogue, a set of specific and distinct objectives co-exist. A set of communities and actors with different capacities and power to affect the dialogue outcome were involved, and the dialogue itself is integrated as part of the regional government agenda. The success of this type of dialogue is then conditioned by the level of pervasiveness of the different actions regulated in the field of STI, which while initially defined to promote development in the regional context, may permit the fruition of only partial and specific results in the communities and even among the individual actors involved.

The Iberdrola dialogue for the mobility of researchers defines a bottom-up approach that seeks to remove certain limitations in labour regulation, and in the end to enhance university-industry relationships in Spain. The lack of connections between different actors is a very common feature in relatively under-developed innovation systems. Although good practices at the global level have shown the positive impact that the promotion of such interactions and linkages between diverse actors may generate, in terms of innovation results, putting those relationships into practice is often met with serious difficulties due to a lack of incentives, or a lack of tradition or culture around collaboration. Here, only a few actors were involved because a large firm presented itself as a leader of the process; universities were also an active and interested actor, while public administration bodies were crucial to the end results. The effects generated due to this process permits to see how the public agenda concerns may become part of the government agenda after a process of dialogue takes place.

Comparing the two processes, the analytical construction can be obtained looking at both the feature of the dialogue definition, the diversity of interests and actors, and the outcome or extent for STI policy actions. It can be said that pervasiveness was the aspect to be most highlighted when considering the objectives of the Regional PAIDI Plan, because many interests and many actors were integrated into the motive behind of the dialogue; the result obtained through the process serve as an instrument for planning actions to take place over a four-year framework in the field of STI (Figure 2). One 
important characteristic of the PAIDI dialogue was the general participation of the most of the RSI actors. This implies that too many interests may reside in the development of the regional plan, while the target interest remains the extension of innovation and growth in the region. Although specific objectives were identified in terms of the promotion of scientific excellence and management of talent, the orientation of $R \& D$ and innovation toward social concerns, and the promotion of $R \& D$ infrastructures, a general impulse of the knowledge economy to foster development in the region raising competitiveness and sectorial innovation was the general objective. Overall, these aspects deal to characterise the dialogue definition as pervasive and how the outcome is specific due to the limited scope of the regional boundaries (Figure 3).

Figure2. Pervasiveness and specificity attributes of STI dialogues

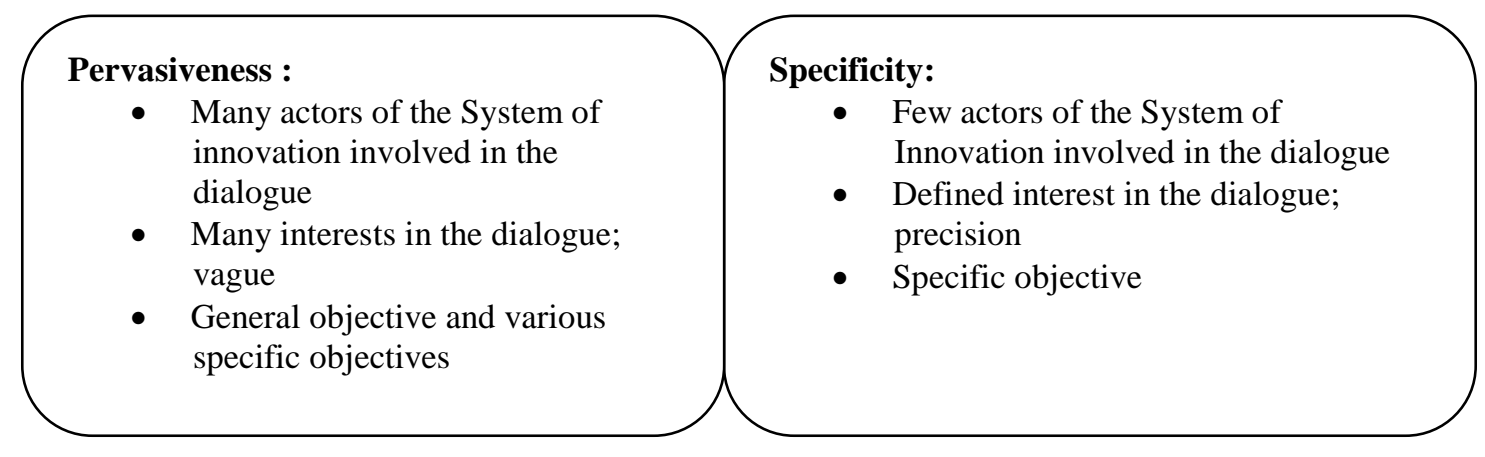

Source: Own elaboration

Figure 3. Characterization of the two dialogues in Spain

\begin{tabular}{|c|c|c|c|c|}
\hline Dialogue & Direction & Actors & Interests & Scope Effect \\
\hline $\begin{array}{c}\text { Regional plan: } \\
\text { "PAIDI" }\end{array}$ & Top-down & $\begin{array}{c}\text { Diverse, } \\
\text { heterogeneous }\end{array}$ & Pervasive & $\begin{array}{c}\text { Specific } \\
\text { geography }\end{array}$ \\
\hline $\begin{array}{c}\text { "Iberdrola": } \\
\text { Mobility of } \\
\text { researchers }\end{array}$ & Bottom-up & $\begin{array}{c}\text { Less diverse, } \\
\text { heterogeneous }\end{array}$ & Specific & $\begin{array}{c}\text { Pervasive } \\
\text { geography }\end{array}$ \\
\hline
\end{tabular}

Source: Own elaboration

The Iberdrola dialogue began with a precise point of interest and the integration of few actors into the process. Interest was shared between a large firm and representative universities seeking to seduce public administrations improving labour regulation 
affecting the integration of young researchers into firms. In the end, the dialogue generated an impact at the level of national law that makes the positive effects of the process more extensive, pervasiveness thus becoming a result of a dialogue initially characterized by specificity (Figure 3). This is due to the consideration of the scope of the effects that a dialogue driven by a clear bottom-up direction may generate in the field of STI and beyond.

Our findings reveal that specific dialogues between diverse actors of the innovation system may carry different implications for STI policy. In particular, the dialogue can itself be conceived as a mechanism capable of generating an impact of such magnitude as to ultimately transform specific characteristics of the system of innovation. One of them is the consideration of how the process of definition and policy implementation is currently operating within the field of STI, and whether dialogues are rooted in the identification of problems solely by government bodies, or whether actors directly involved also contribute a dimension. Another factor is related to the results that can be achieved by an innovation strategy based on building domestic capabilities that would, in the end, act as a lever for development (Lundvall et al., 2009). In that vein, an important concern is how different public policy fields ought to be combined within the triple helix system framework, considering the complexity of innovation dynamics. Key arguments in this discussion suggest the existence of a two-way connection between dialogues processes for the elaboration of STI policies and the characteristics of the system of innovation, their capacities and boundaries, with implications for developing contexts and for international comparisons.

\section{Conclusions}

The study of successfully dialogues and their characteristics driving to STI policy actions that has been presented in previous sections, permits to argue about the importance of considering the diversity of actors and interests, as well as the particular scope and targets in the field of STI policy. In particular, findings allow us to observe dialogue as an innovative construct, able to transform initially specific interests to pervasive effects through the socialization of learning. The issue is that actors involved in a long-lasting process of conversation are able to alter their initial convictions according to what they learn from others. These dialogues can be then conceived as a transformative process that combines aspects of specificity and pervasiveness into a 
unique dynamic revealing how the motivations of dialogue may be transformed into differentiated effects.

Our findings corroborate the pertinence of initiatives than being specifically oriented to particular interests, may derive into more pervasive effects in the STI field. The direct generalizable implication would be the reinforcement of bottom-up processes that would affirm local and specific knowledge about weaknesses and needs as key aspects for STI policy action in developing contexts. Moreover, the consideration of the different capabilities level as well as the existence of heterogenous actors can be argued as key factors in the development of a dialogue methodology.

Further research will address specificity and pervasiveness as key analytical categories identifiable within existing dialogues, whether still in process or having already promoted STI actions. The findings may permit further advance in terms of adopting a methodology for dialogue that can make STI policies more effective in a developing context. Next steps in this line of research would include the comparison of dialogues that have taken place in Latin American countries in the framework of the CYTEDLalics network. Comparison of dialogues in that region, within different local contexts, would provide sufficient diversity for achieving methodological advances, in order to identify common dimensions and to test the hypothesises of pervasiveness and specificity. The application of qualitative research methods, and greater in-depth analysis of the facilitating and blocking elements found in dialogues for STI policy, would then permit a more solid validation of this analytical framework. 


\section{Acknowledgement}

Authors acknowledge the support of CYTED through the thematic network entitled "Red temática para mejorar el diálogo entre las comunidades involucradas en las políticas de CTI (COM-LALICS)". This CYTED network has been established as an initiative of the "Latin American network for economics of learning, innovation and competence building systems (LALICS, http://www.lalics.org)”. 


\section{References}

1. Aguilar, L. (1992). "El estudio de las políticas públicas. Antologías I. México: Miguel Ángel Porrúa.

2. Álvarez, I., Barletta, F., Suarez, D., Yoguel, G. (2016). "Marco analítico para la tipificación de diálogos para las políticas de CTI”. Working paper Red COMLALICS-CyTED -internal document.

3. Anderson, J. E. (2003). Public policymaking: An introduction, $5^{\text {th }}$ edn. Boston, MA: York Houghton Mifflin.

4. Arellano, D. (1996). "Política pública, racionalidad imperfecta e irracionalidad: hacia una perspectiva diferente”. Gestión y Política Pública, 5 2, 319-347.

5. Brown, M. (2015). "Politicizing science: Conceptions of politics in science and technology studies”. Social Studies of Science 2015. Vol.45 1 3-30.

6. Burgess, J. And Chilvers, J. (2006). "Upping the ante: a conceptual framework for designing and evaluating participatory technology assessments”. Science and Public Policy, volume 33, number 10, pp: 713-728.

7. Carlsson, B. (2006). "Internationalization of innovation systems: A survey of the literature”. Research policy, 351, pp. 56-67.

8. Castellacci, F. and Natera, J. M. (2012). "Innovation surveys in Latin America: a primer”. MPRA Paper 37769, University Library of Munich, Germany.

9. Chilvers J. (2012). "Reflexive Engagement? Actors, learning and reflexivity in Public Dialogue on Science and Technology”. Science Communication, 353.

10. Chilvers, J. (2010). "Sustainable Participation? Mapping out and reflecting on the field of public dialogue on science and technology". Working Paper. Sciencewise Expert Resource Centre, Harwell.

11. Cobb, R., and Elder C. (1972). "Participation in American politics: The dynamics of agenda building”. Baltimore: The John Hopkins University Press.

12. Cooke, P. (1992). "Regional Innovation Systems: Competitive Regulation in the New Europe”. Geoforum. 23: 365-382.

13. Crespi, G., and Dutrenit, G. (2013). "Políticas de ciencia, tecnología e innovación para el desarrollo: experiencia latinoamericana”. Foro consultivo científico y tecnológico, A.C. Mexico.

14. De León, P. (1988). Advice and consent: The development of the policy sciences. Nueva York: The Russell Sage Foundation.

15. Duran, D. (2010). "Public participation in the making of science policy". Perpective on Science. Volume 18, Number 2, pp: 189-225.

16. Edquist, C. (2004). "Systems of innovation: perspectives and challenges", in: Fagerberg, J., Mowery, D., Nelson, R. Eds. The Oxford handbook of innovation. Oxford University Press, USA.

17. Edquist, C., and Hommen, L. (2008). Small country innovation systems: Globalization, change and policy in Asia and Europe. Edward Elgar Publishing.

18. Edquist, C., Hommen, L. (1999). "Systems of innovation: theory and policy for the demand side”. Technology in society”. 21, 63-79.

19. Etzkowitz, H. (1993), 'Technology transfer: the second academic revolution', Technology Access Report, No 6, pp 7-9.

20. Etzkowitz, H., Mello, J.M.C., and Almeida, M. (2005), 'Towards “'metainnovation' in Brazil: the evolution of the incubator and the emergence of a Triple Helix', Research Policy, Vol 34, No 4, pp 411-424. 
21. Etzkowitz, H., and Leydesdorff, L. (1995), 'The Triple Helix: universityindustry-government relations: a laboratory for knowledge-based economic development', EASST Review, Vol 14, pp 14-19.

22. Fagerberg, J., and Sapprasert, K. (2011). "National innovation systems: The emergence of a new approach". Science and Public Policy, 389, 669-679.

23. Felt, U., and Fochler, M., (2009). "The bottom-up meaning of the concept of public participation in Science and technology”. Science and Public Policy 357: 489-499.

24. Freeman, C. (1987). Technology Policy and Economic Performance: Lessons from Japan. London, Frances Pinter.

25. García Arroyo, A., López Facal, J., Muñoz, E., Sebastián, J., and Tortosa, E. (2007). "Legislar sobre política científica para el siglo XXI en España. Un nuevo marco normativo para la política de I+D”. Arbor, vol. CLXXXIII, n ${ }^{\circ}$ 727, pp. 637-654.

26. García Sánchez, A., Borra Marcos, C., and Espasandín Bustelo, F. (2005). "El Comportamiento Innovador de las Empresas Andaluzas de Economía Social”. Comunicación en congreso. Encuentro de Economía Aplicada. Murcia, España. 2005. VIII Encuentro de Economía Aplicada. 1. 25.

27. Hellström, T. (1996). "The science-policy dialogue in transformation: modeluncertainty and environmental policy”. Science and Public Policy, 232, 91-97.

28. Lasswell, H. D., \& Lerner, D. (1951). The policy sciences. Stanford University Press.

29. Lowe, C.U. (1982), 'The Triple Helix - NIH, industry, and the academic World', Yale Journal of Biology and Medicine, Vol 55, pp 239-246.

30. Lundvall, B., Joseph, K., Chaminade, C., and Vang, J. (2009). Handbook of innovation systems and developing countries: Building domestic capabilities in a global setting Edward Elgar Publishing.

31. Lundvall, B.-A. (1988). "Innovation as an Interactive Process: From UserProducer Interaction to National Systems of Innovation”. In G. Dosi, C. Freeman, R. Nelson, et al. Eds. Technical Change and Economic Theory. Londres/Nueva York: Pinter Publishers.

32. Lundvall, B.-A. (1992). National Systems of Innovation: Towards a Theory of Innovation and Interactive Learning, London, Pinter.

33. Lundvall, B.-A. (2007). "National innovation systems-analytical concept and development tool”. Industry and innovation, 141, pp. 95-119.

34. Nelson, B. (2001). "Políticas públicas y administración: Una visión general”. In Goodin, R. and Klingemann, H. Eds. Nuevo Manual de Ciencia Política. Tomo II. Madrid, Istmo. 795 - 860.

35. Nelson, R. R. (1992). "National Innovation Systems. A Retrospective on a Study". Industrial and Corporate Change. 12 : 347-374.

36. Nelson, R. R. (1993). National Innovation Systems. A Comparative Analysis. Nueva York/Oxford: Oxford University Press.

37. Nelson, R. R. (2008). "What enables rapid economic progress: What are the needed institutions?” Research Policy, 371, 1-11.

38. OCDE (2011). Hacia un mecanismo para el diálogo de políticas de innovación. Oportunidades y desafíos para América Latina y el Caribe, OCDE.

39. Palma Martos, L., Martín Navarro, J. L., Rodríguez Ramos A. (1992). “Cambio tecnológico y desarrollo regional: la política tecnológica en Andalucía 19801992”. Cuadernos de estudios empresariales n² 2, pp. 147-160. 
40. Pavitt, K., (1984). "Sectoral patterns of technical change: towards a taxonomy and a theory”. Research Policy 13 (6), 343-373.

41. Pieczka M. (2002). "Public relations expertise deconstructed". Culture and Society; 24:301-23.

42. Pieczka, M., and Escobar, O. (2013). "Dialogue and science: Innovation in policy-making and the discourse of public engagement in the UK”. Science and Public Policy, 401, 113-126.

43. PNUD, 2003. Mapeo de experiencias de diálogo en América Latina y el Caribe. lineamientos de investigación, matriz y variables. Proyecto regional de diálogo democrático para América Latina y el Caribe

44. Cuentas, M.A., Méndez A.L. 2007. Guia práctica del diálogo democrático. PNUD

45. Ranga, M., \& Etzkowitz, H. (2013). Triple helix systems: An analytical framework for innovation policy and practice in the knowledge society. Industry and Higher Education, 27, 237-262.

46. Sábato, J., and Mackenzi, M. (1982), La Producción de Tecnología: Autónoma o Transnacional, Nueva Imagen, Mexico.

47. Sanz-Menéndez, L. and Muñoz, E. (1994). "Technology policy in Spain: issues, concerns and problems". In G. Aichholzer and G. Schienstock (eds). Technology policy: towards an integration of social and ecological concerns. De Gruyter, Berlin-New York.

48. Stirling A., (2008). "Opening up and closing down. Power, participation and pluralism in the social appraisal of technology”. Science, Technology and Human values. Volume 33. Number 2. Pp: 262-294.

49. Sutz J., (1993). “Innovación e integración en América Latina. Nuevos Puntos para una vieja Agenda”. Nueva sociedad n 126, julio - agosto de 1993, pp. 8497

50. Uyarra, E. (2010). "What is evolutionary about regional systems of innovation? Implications for regional policy”. Journal of Evolutionary Economics, 201, 115137.

51. Von Hippel, E. (1988). The sources of innovation. New York. 